\title{
ATP-Sensitive Potassium Channel-Mediated Lactate Effect on Orexin Neurons: Implications for Brain Energetics during Arousal
}

\author{
Matthew P. Parsons and Michiru Hirasawa \\ Division of BioMedical Sciences, Faculty of Medicine, Memorial University, St. John's, Newfoundland and Labrador A1B 3V6, Canada
}

Active neurons have a high demand for energy substrate, which is thought to be mainly supplied as lactate by astrocytes. Heavy lactate dependence of neuronal activity suggests that there may be a mechanism that detects and controls lactate levels and/or gates brain activation accordingly. Here, we demonstrate that orexin neurons can behave as such lactate sensors. Using acute brain slice preparations and patch-clamp techniques, we show that the monocarboxylate transporter blocker $\alpha$-cyano-4-hydroxycinnamate (4-CIN) inhibits the spontaneous activity of orexin neurons despite the presence of extracellular glucose. Furthermore, fluoroacetate, a glial toxin, inhibits orexin neurons in the presence of glucose but not lactate. Thus, orexin neurons specifically use astrocyte-derived lactate. The effect of lactate on firing activity is concentration dependent, an essential characteristic of lactate sensors. Furthermore, lactate disinhibits and sensitizes these neurons for subsequent excitation. 4-CIN has no effect on the activity of some arcuate neurons, indicating that lactate dependency is not universal. Orexin neurons show an indirect concentration-dependent sensitivity to glucose below $1 \mathrm{~mm}$, responding by hyperpolarization, which is mediated by ATP-sensitive potassium channels composed of Kir6.1 and SUR1 subunits. In conclusion, our study suggests that lactate is a critical energy substrate and a regulator of the orexin system. Together with the known effects of orexins in inducing arousal, food intake, and hepatic glucose production, as well as lactate release from astrocytes in response to neuronal activity, our study suggests that orexin neurons play an integral part in balancing brain activity and energy supply.

\section{Introduction}

The brain, although comprising only $\sim 2 \%$ of body weight, is responsible for $25 \%$ of total body glucose utilization, necessitating a continuous supply from the periphery (Magistretti et al., 1995). This is thought to be ensured by the glucose homeostatic mechanism involving "glucosensors" that exist in the hypothalamus and brainstem (Levin et al., 2004; Marty et al., 2007). Glucosensing neurons are excited [glucose excited (GE)] or inhibited [glucose inhibited (GI)] by extracellular glucose and induce appropriate counterregulatory responses to restore glucose homeostasis (Levin, 2001). Glucosensing in certain GE and GI neurons depends on glucokinase, a critical enzyme that catalyzes glycolysis (Lynch et al., 2000; Dunn-Meynell et al., 2002; Kang et al., 2004; Balfour et al., 2006), suggesting that glucose metabolism is directly involved in their electrophysiological response to glucose.

Although some neurons clearly use glucose, astrocytes seem to be the main cell type that metabolizes glucose in the active brain, providing neurons with lactate as an energy substrate (Pellerin and Magistretti, 1994; Pellerin et al., 2007). Because of the heavy

Received Nov. 19, 2009; revised April 21, 2010; accepted April 29, 2010.

This work was supported by the Canadian Institutes of Health Research. M.P.P. is a Heart and Stroke Foundation of Canada Fellow. We thank Drs. Quentin J. Pittman and Jacqueline Vanderluit for the critical reading of this manuscript and Christian 0. Alberto for technical assistance.

Correspondence should be addressed to Dr. Michiru Hirasawa, Division of BioMedical Sciences, Faculty of Medicine, Memorial University, 300 Prince Philip Drive, St. John's, NL A1B 3V6, Canada. E-mail: michiru@mun.ca.

D01:10.1523/JNEUROSCI.5741-09.2010

Copyright $\odot 2010$ the authors $\quad 0270-6474 / 10 / 308061-10 \$ 15.00 / 0$ lactate dependence, it is plausible that the brain has mechanisms to monitor lactate levels and control energy substrate levels. Mediobasal hypothalamic GE neurons not only respond to glucose but also to lactate, suggesting that they may also act as lactate sensors (Yang et al., 1999; Ainscow et al., 2002). However, as glucose and lactate do not always fluctuate in tandem within the brain, it is important to determine whether neuronal sensors exist that have selective sensitivity to lactate.

Orexin neurons induce food intake (Sakurai et al., 1998) and regulate autonomic functions (Ferguson and Samson, 2003), including stimulation of hepatic glucose production (Yi et al., 2009). Furthermore, these neurons play an important role in wakefulness (Hagan et al., 1999; Sakurai, 2007) through widespread projections to major arousal-related cell groups (Date et al., 1999). Therefore, orexin neurons are well suited to correlate brain activity and energy supply. Previous studies show that orexin neurons are GI, inhibited by increases and excited by decreases in extracellular glucose in a metabolism-independent manner (Yamanaka et al., 2003; Burdakov et al., 2005, 2006). This glucose effect is acute and mostly short-lived, as the majority of orexin neurons adapt to the new glucose level within several minutes (Williams et al., 2008). This suggests that orexin neurons sense rapid changes rather than the absolute concentration of glucose. However, the time course of glucose fluctuations is not rapid in the lateral hypothalamus where orexin neurons are located (Voigt et al., 2004), and it remains uncertain how orexin neurons respond to slower and longer changes in glucose levels. Furthermore, orexin neurons lack detectable levels of glucoki- 
nase (Dunn-Meynell et al., 2002) and are excited by lactate (González et al., 2008), indicating that these neurons may rely on lactate as a main energy source. Here, we demonstrate that orexin neurons do not directly sense glucose but instead detect astrocyte-derived lactate, which is translated into varying levels of neuronal activity. Our results provide insight into how orexin neurons may integrate the energy status of the brain as lactate sensors and orchestrate coordinated physiological responses.

\section{Materials and Methods}

All experiments were performed following the guidelines set out by the Canadian Council on Animal Care and approved by the Memorial University Institutional Animal Care Committee. Male Sprague Dawley rats $(60-70 \mathrm{~g})$ were obtained from the breeding colony at Memorial University and $\mathrm{C} 57 \mathrm{BL} / 6 \mathrm{NCrl}$ mice (3-4 weeks) from Charles River Laboratories.

Electrophysiology. Animals were deeply anesthetized with halothane and decapitated, and brains were quickly removed. Coronal hypothalamic slices $(250 \mu \mathrm{m})$ were sectioned in ice-cold artificial CSF (ACSF) composed of the following (in mM): $126 \mathrm{NaCl}, 2.5 \mathrm{KCl}, 1.2 \mathrm{NaH}_{2} \mathrm{PO}_{4}, 1.2$ $\mathrm{MgCl}_{2}, 25 \mathrm{NaHCO}_{3}, 2 \mathrm{CaCl}_{2}, 2.5$ glucose, $\mathrm{pH}$ 7.3-7.35. After dissection, slices were incubated in ACSF at $32-35^{\circ} \mathrm{C}$ for $30-45 \mathrm{~min}$, and then at room temperature until recording. ACSF was continuously bubbled with $\mathrm{O}_{2}(95 \%) / \mathrm{CO}_{2}(5 \%)$.

Patch-clamp recordings were performed on brain slices perfused with ACSF at $1.5-2 \mathrm{ml} / \mathrm{min}, 32-35^{\circ} \mathrm{C}$, using a Multiclamp $700 \mathrm{~B}$ amplifier and pClamp 9.2 (Molecular Devices). The glucose concentration used for recording was $2.5 \mathrm{~mm}$ unless otherwise noted. The internal solution for conventional whole-cell recordings contained the following (in mM): 123 K-gluconate, $2 \mathrm{MgCl}_{2}, 8 \mathrm{KCl}, 0.2$ EGTA, 10 HEPES, $4 \mathrm{Na}_{2}$-ATP, 0.3 $\mathrm{Na}-\mathrm{GTP}, \mathrm{pH}$ 7.3. $\mathrm{Na}_{2}$-ATP was omitted for the ATP-free internal solution. In a subset of experiments, the composition of ACSF and internal solution were as previously described (Burdakov et al., 2006; González et al., 2008). For these experiments, the ACSF consisted of the following (in mM): $125 \mathrm{NaCl}, 2.5 \mathrm{KCl}, 2 \mathrm{MgCl}_{2}, 2 \mathrm{CaCl}_{2}, 1.2 \mathrm{NaH}_{2} \mathrm{PO}_{4}, 21 \mathrm{NaHCO}_{3}, 10$ HEPES, 1.0 glucose, $\mathrm{pH}$ 7.3. The intracellular solution consisted of the following (in mM): $120 \mathrm{~K}$-gluconate, $10 \mathrm{KCl}, 0.1 \mathrm{EGTA}, 10 \mathrm{HEPES}, 4$ $\mathrm{K}_{2} \mathrm{ATP}, 1 \mathrm{Na}_{2} \mathrm{ATP}, 2 \mathrm{MgCl}_{2}, \mathrm{pH}$ 7.3. For perforated patch-clamp recordings, nystatin $(0.45 \mathrm{mg} / \mathrm{ml}$ final $)$ and pluronic acid were dissolved in DMSO and added to an internal solution that contained the following (in $\mathrm{mm}$ ): $120 \mathrm{~K}$-gluconate, $5 \mathrm{MgCl}_{2}, 10$ EGTA, and 40 HEPES, pH 7.3. Biocytin $(1-1.5 \mathrm{mg} / \mathrm{ml})$ was also included in the conventional whole-cell and nystatin internal solutions for post hoc immunohistochemical phenotyping. To aid biocytin entry into nystatin-perforated cells, a positive current was applied for 2-5 min after experimentation (Hirasawa et al., 2003). Cell-attached patch experiments used a $150 \mathrm{~mm} \mathrm{NaCl}$ pipette solution. After cell-attached experiments, cells were repatched in whole-cell mode for electrophysiological and immunohistochemical characterization.

Orexin neurons displayed spontaneous firing as well as $I_{\mathrm{h}}$, lowthreshold spike and minimal spike adaptation in response to $300 \mathrm{~ms}$ negative and positive current steps ( -200 to $+200 \mathrm{pA}$ in $100 \mathrm{pA}$ increments). These characteristics were clearly distinguishable from those of melanin-concentrating hormone $(\mathrm{MCH})$ neurons that were also localized in the same region (Eggermann et al., 2003; Alberto et al., 2006). Furthermore, the presence or absence of action potential firing immediately after the offset of a hyperpolarizing current step was used to differentiate D- and H-type orexin neurons, respectively (Williams et al., 2008). A total of 148 of the recorded cells that had typical electrophysiological characteristics of orexin neurons was successfully filled with biocytin, and of these, 134 cells (90.5\%) were orexin A immunopositive. Because of the high success rate of deducing the neurochemical phenotype from the electrophysiological criteria, these criteria were used for identifying orexin cells for additional analysis. Voltage-clamp experiments were performed at a holding potential of $-70 \mathrm{mV}$. In a subset of cells, voltage ramps ( -140 to $0 \mathrm{mV}$ in $1.4 \mathrm{~s}$ or -140 to -20 in $0.6 \mathrm{~s}$ ) were applied to determine current-voltage relationships. To examine the ef- fect of positive current injection on the firing activity, a current ramp from 0 to $100 \mathrm{pA}$ was applied over $5 \mathrm{~s}$ in current-clamp mode.

Immunohistochemistry. Immunohistochemical phenotyping of recorded neurons was performed as previously described (Alberto et al., 2006). Briefly, immediately after recording, sections were fixed in $10 \%$ formalin for $>48 \mathrm{~h}$, and then treated with a mixture of goat anti-orexin A (1:2000; Santa Cruz Biotechnology) and rabbit anti-MCH (1:2000; Phoenix Pharmaceuticals) antibodies for $3 \mathrm{~d}$ at $4^{\circ} \mathrm{C}$, followed by cyanine (Cy)3-conjugated donkey anti-goat, Cy2-conjugated donkey anti-rabbit, and streptavidin-conjugated AMCA (7-amino-4-methylcoumarin-3acetic acid) (1:500; Jackson ImmunoResearch). For immunohistochemical analysis of Kir subunits, fresh-frozen sections $(10-15 \mu \mathrm{m})$ of rat brains were fixed with $4 \%$ paraformaldehyde for $5 \mathrm{~min}$, and then treated sequentially with antibodies in the following order: rabbit anti-Kir6.1 (1:100; Alomone Labs) or rabbit anti-Kir6.2 (1:100; Santa Cruz Biotechnology), $2 \mathrm{~d}$ at $4^{\circ} \mathrm{C}$; Cy2-donkey anti-rabbit (1:500), $5 \mathrm{~h}$ at room temperature; goat anti-orexin $\mathrm{A}(1: 1000)$, overnight at $4^{\circ} \mathrm{C}$; Cy3donkey anti-goat (1:500), $3 \mathrm{~h}$ at room temperature. Immunofluorescence was visualized using a confocal microscope (FV300 scan head, BX50WI upright microscope; Olympus). Cy2 and Cy3 signals were scanned sequentially through a three-section stack in $z$-step increments of $1 \mu \mathrm{m}$. The three images were stacked together using Fluoview software (Olympus), saved as separate Cy2 and Cy3 images, which were combined in Corel PaintShop Pro Photo XI. Minor adjustments were made in PaintShop to optimize brightness and contrast.

Data analysis. Action potential frequency, membrane potential, and holding current were measured using Mini Analysis 6.0 (Synaptosoft) and Clampfit 9.2 (Molecular Devices). Data are expressed as mean \pm SEM. Instantaneous action potential frequency was calculated as the inverse of each action potential interval. A $15 \%$ or greater change in firing frequency was considered significant for individual cells. Statistical tests used included one-way ANOVAs for multiple-group comparisons and paired and unpaired Student's $t$ tests for two-group comparisons. Tukey's multiple-comparison tests were performed when ANOVA found significance. A value of $p<0.05$ was considered significant. Calculation of the $\mathrm{EC}_{50}$ was performed by fitting the experimental data with the sigmoidal dose-response equation (variable slope) using Prism 4 (GraphPad).

Drugs. The $1000 \times$ aliquots of drugs were diluted with ACSF to the final concentration immediately before each experiment. All drugs were obtained from Sigma-Aldrich, except glibenclamide and pinacidil (Tocris Bioscience) and tetrodotoxin (TTX) (Alomone Labs). Tolbutamide was dissolved in DMSO with a final DMSO concentration of $0.1 \%$.

\section{Results}

\section{Orexin neurons selectively use lactate to fuel spontaneous activity}

To determine whether lactate is preferentially used by orexin neurons, we used $\alpha$-cyano-4-hydroxycinnamate (4-CIN), a specific inhibitor of monocarboxylate transporters (MCTs), which are responsible for lactate transport across the plasma membrane. In cell-attached mode, the spontaneous firing of orexin neurons was significantly inhibited by $0.5 \mathrm{mM} 4$-CIN [control (CTL), $2.6 \pm 0.4 \mathrm{~Hz}$, vs $4-\mathrm{CIN}, 0.7 \pm 0.9 \mathrm{~Hz} ; p<0.05$; $n=6$ ] (Fig. 1A).

To further establish the role of lactate, we tested whether or not exogenous lactate is sufficient to support the firing activity of orexin neurons in the absence of glucose. First, extracellular glucose was removed for $20 \mathrm{~min}$ to determine the behavior of orexin neurons in glucose-free conditions. Cell-attached recordings revealed a complete but reversible cessation of firing activity in 9 of 10 cells (Fig. $1 B$ ), indicating that glucose is necessary for spontaneous activity. Results were similar regardless of the baseline glucose being 2.5 or $10 \mathrm{~mm}$; thus, data were combined. Inhibition induced by glucose deprivation had a relatively long latency $(13.6 \pm 1.2 \mathrm{~min})$ that did not differ from that of the 4 -CIN effect $(14.6 \pm 2.1 \mathrm{~min} ; p>0.05)$. In perforated-patch whole-cell re- 

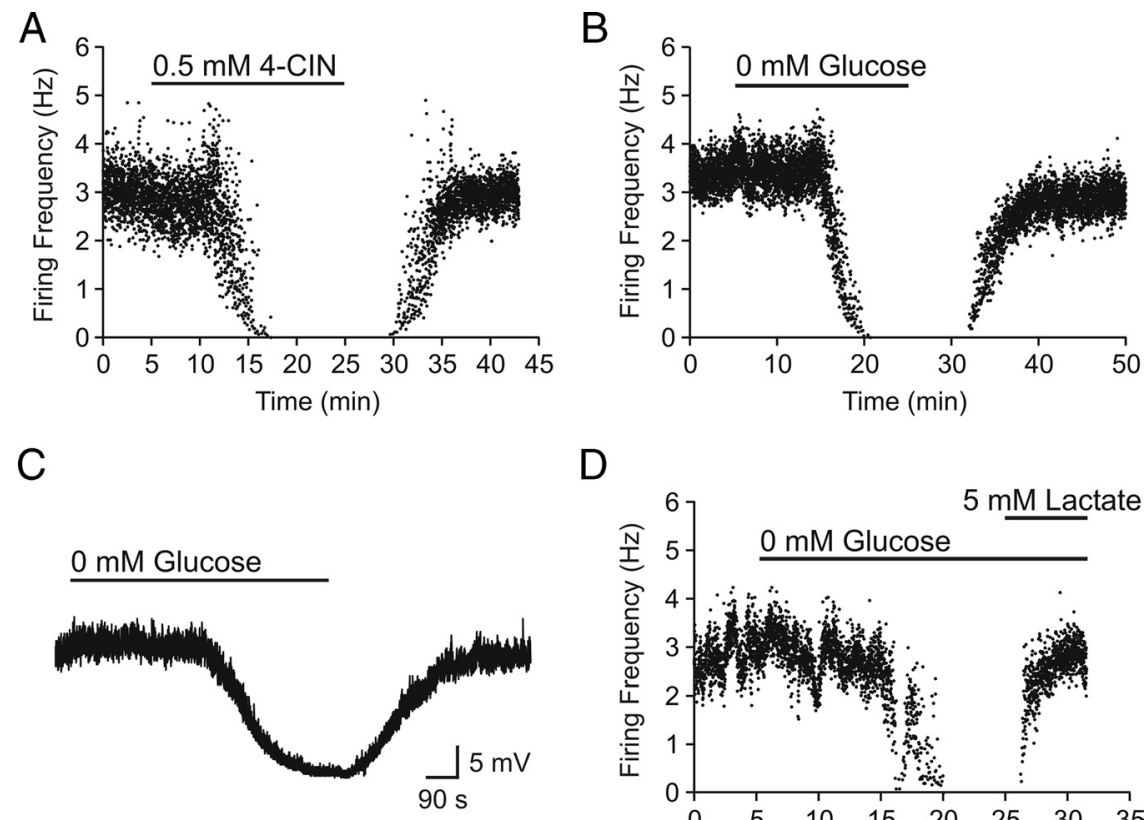

D
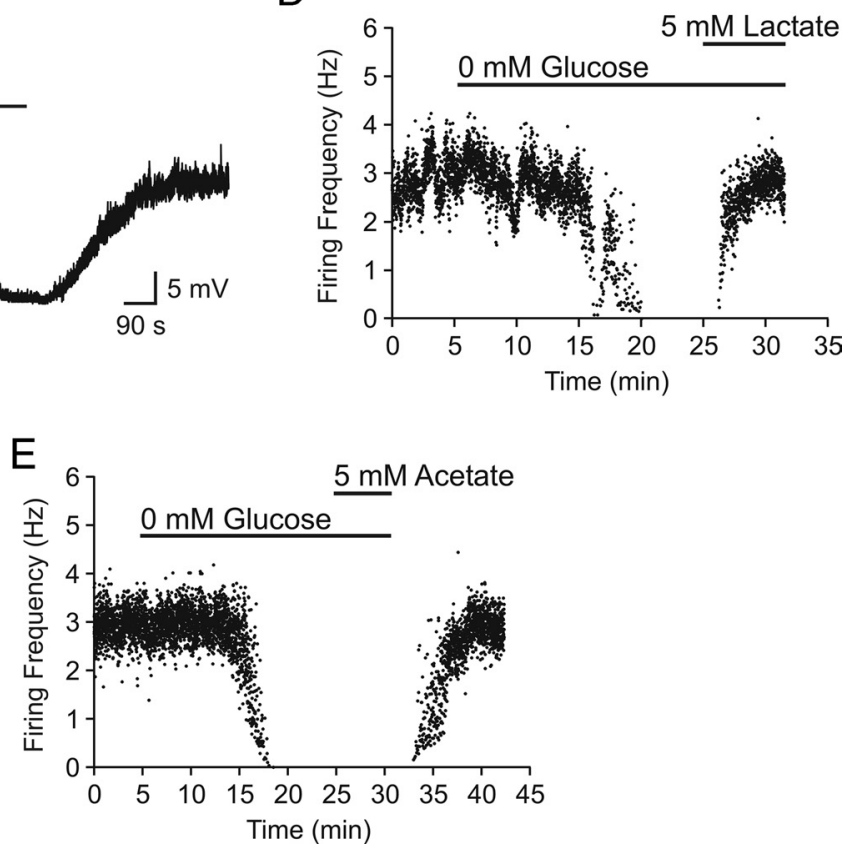

Figure 1. Lactate is necessary and sufficient to maintain basal levels of spontaneous activity in orexin neurons. $\boldsymbol{A}$, Representative time- effect plot showing an inhibitory effect of 4-CIN on the firing frequency of an orexin neuron in the presence of $2.5 \mathrm{~mm}$ glucose. $\boldsymbol{B}$, Representative experiment showing an inhibitory effect of complete glucose deprivation. $\boldsymbol{C}$, Glucose deprivation induces a TTX-insensitive reversible hyperpolarization. $\boldsymbol{D}, \boldsymbol{E}$, The $0 \mathrm{~mm}$ glucose effect is completely reversed by lactate $(\boldsymbol{D})$ but not by acetate $(\boldsymbol{E})$.

cordings, hyperpolarization was induced by $0 \mathrm{~mm}$ glucose in the presence of $1 \mu \mathrm{M}$ TTX $(n=2)$ (Fig. 1C), suggesting a direct postsynaptic effect. In an additional four cells that were silenced by the lack of glucose, lactate $(5 \mathrm{~mm})$ completely restored their firing activity (119.8 $\pm 38.4 \%$ of baseline firing frequency) (Fig. $1 D)$. Because lactate can be used as a fuel by both neurons and astrocytes (Tabernero et al., 1996; Ainscow et al., 2002), it is possible that the lactate effect on neuronal firing activity was mediated by neighboring astrocytes taking up lactate, which in turn stimulated neurons. To test this possibility, we tested acetate, which is used by astrocytes but not neurons (Waniewski and Martin, 1998). Acetate should mimic lactate if astrocytes are responsible for metabolizing and mediating the lactate effect. However, bath application of acetate ( $5 \mathrm{~mm}$ ) was unable to reverse the silencing effect of glucose deprivation on orexin neurons $(n=3)$ (Fig. 1E), indicating that astrocytes did not mediate the excitatory effect of lactate on orexin neurons.

Astrocytes are also known as the major cell type that metabolizes glucose and releases lactate into the extracellular space (Pellerin and Magistretti, 1994). Therefore, we hypothesized that orexin neurons depend on lactate released endogenously by astrocytes. To test this hypothesis, hypothalamic slices were pre- treated with the glial toxin fluoroacetate (FAC) (5 mM; 50-80 min). During the final $20 \mathrm{~min}$, glucose was removed to deplete any existing energy substrates. Then, either glucose $(1-2.5 \mathrm{~mm} ; n=11)$ or equicaloric lactate $(2-5 \mathrm{~mm} ; n=9)$ was applied in the continuing presence of FAC, at which time the firing rate was examined using conventional whole-cell patch clamp. The control group only received glucose deprivation for $20 \mathrm{~min}$ followed by glucose restoration $(n=7)$. As shown in Figure 2, we found that FAC prevented glucose from reversing the firing activity of the orexin neuron to the control level. In contrast, exogenous lactate after glucose deprivation completely restored the firing rate in FAC-treated cells. Together, these data suggest that, within the slice preparation, lactate is necessary and sufficient to maintain the spontaneous activity of orexin neurons and that glucose is converted to lactate endogenously by astrocytes.

\section{ATP-sensitive potassium channels mediate lactate sensing}

ATP-sensitive potassium (KATP) channels are prime candidates that mediate the lactate effect on firing frequency and membrane potential (Ashford et al., 1990; Song et al., 2001). Using perforated patchclamp recordings, we found that the hyperpolarization induced by glucose deprivation (from $-46.7 \pm 1.0$ to $-61.1 \pm$ $4.6 \mathrm{mV} ; n=4 ; p<0.05$ ) (Fig. $3 A$ ) was blocked by glibenclamide, the KATP channel blocker, suggesting that KATP channels mediate the hyperpolarization. In fact, in every cell tested, glibenclamide unmasked a depolarization (from $-44.9 \pm$ 1.3 to $-33.6 \pm 2.3 \mathrm{mV}$ in glucose-free condition; $n=5 ; p<0.001$ ) (Fig. $3 B$ ), which led to irreversible cell damage that could not be rescued even with $10 \mathrm{~mm}$ glucose up to $60 \mathrm{~min}$. The fact that glibenclamide-treated cells appeared unable to survive a $20 \mathrm{~min}$ glucose deprivation period suggests a neuroprotective role of KATP channels in orexin neurons during severe energy depletion. To confirm the role of lactate in the glucose deprivation effect, we tested the KATP channel blocker tolbutamide (1 mM) on the 4-CIN-induced inhibition of orexin neurons as seen in Figure $1 A$. We found that tolbutamide significantly attenuated the effect of $0.5 \mathrm{~mm} 4$-CIN $(n=$ 4) (Fig. 3C).

Interestingly, we found that the activity of arcuate neurons of an unknown phenotype was independent of lactate uptake. A 20 min application of 4 -CIN $(0.5 \mathrm{~mm})$ had no effect on the firing frequency of arcuate neurons recorded using perforated patch clamp $(n=4)$ (Fig. 3C,D), whereas 20 min glucose deprivation induced a depolarization similar to that seen in orexin neurons when KATP channels are blocked (Fig. $3 B, D$ ). Thus, lactate availability is monitored by KATP channels in orexin neurons and lactate preference is at least somewhat unique to this particular phenotype. 
A

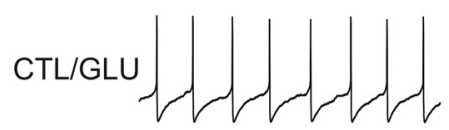

FAC/GLU

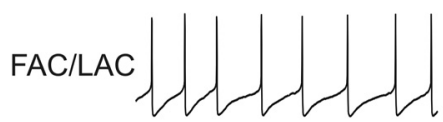

$\downarrow 20 \mathrm{mV}$

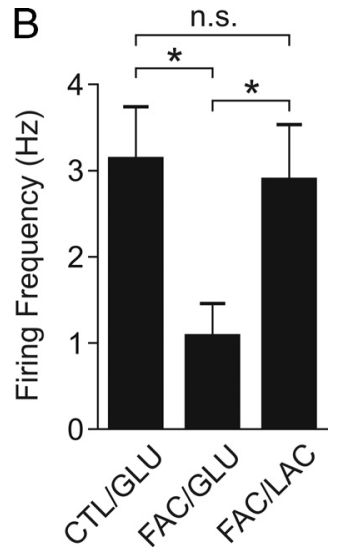

Figure 2. Astrocytes supply lactate to support the spontaneous activity of orexin neurons. $A$, Sample traces of action potentials from representative orexin neurons in the presence of glucose (GLU) or lactate (LAC) in nontreated (CTL) or FAC-treated slices. Grouped data are shown in $\boldsymbol{B} .{ }^{*} p<0.05$. n.S., Nonsignificant. Error bars indicate SEM.

\section{Kir6.1 and SUR1 subunits comprise KATP channels in orexin neurons}

KATP channels are composed of four identical pore-forming subunits (Kir6.1 or 6.2) and four identical modulatory sulfonylurea subunits (SUR1, 2A, or 2B). Double immunofluorescence labeling was conducted to determine the subunit composition of KATP channels in orexin neurons, which revealed the expression of Kir6.1 but not Kir6.2 (Fig. 4A-F). Furthermore, using conventional whole-cell recordings, we found that $0.2 \mathrm{~mm}$ diazoxide, the SUR1/2B-containing KATP channel opener, induced an outward current $(n=11)$ (Fig. 4G,I). The diazoxide-induced current was sensitive to the KATP channel blocker glibenclamide $(n=5)$ (Fig. 4I), insensitive to TTX $(n=3)$ (Fig. $4 G)$, and reversed near the potassium equilibrium potential $(-87.6 \pm 1.4 \mathrm{mV} ; n=4)$ (Fig. $4 H$ ). In contrast, the SUR2A/2B-containing KATP channel opener pinacidil (0.25-0.75 mM) had no effect $(n=8)$ (Fig. $4 I)$. Thus, KATP channels in orexin neurons are composed of Kir6.1 and SUR1 subunits.

To confirm the metabolism-dependent modulation of KATP channels in orexin neurons, we manipulated intracellular ATP levels. Conventional whole-cell recordings with an ATP-free pipette solution were used to dilute cytosolic ATP. This induced a glibenclamide-sensitive outward current in 5-15 min after break-in $(n=5)$ (Fig. $4 J)$. Furthermore, to inhibit metabolism, the mitochondrial uncoupler carbonylcyanide $m$-chlorophenylhydrazone (CCCP) ( $2 \mu \mathrm{M})$ was bath applied, which resulted in a sustained outward current in both conventional and perforated whole-cell configurations $(n=12)$. The effect of CCCP was also blocked by glibenclamide $(n=5)$ (Fig. $4 J)$. These results suggest that KATP channels expressed in orexin neurons are sensitive to the metabolic state of the cell.

\section{Orexin neurons are lactate sensors}

Lactate sensors need to be capable of detecting differences in lactate concentrations within a certain range and converting these differences into specific output signals. To determine whether orexin neurons have the characteristics of lactate sensors, conventional whole-cell recordings were performed on orexin neurons in hypothalamic slices incubated $(>20 \mathrm{~min})$ with various concentrations of lactate in the absence of glucose $(n=4$ for each concentration). The effect of lactate on the firing rate was found to be concentration dependent $\left(\mathrm{EC}_{50}=2.1 \mathrm{~mm}\right.$ ) (Fig. $5 \mathrm{~A}$ ), indicating that these neurons can act as lactate sensors.

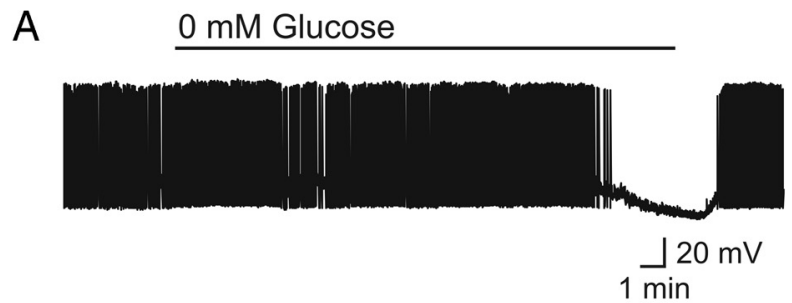

B

200 nM Glibenclamide
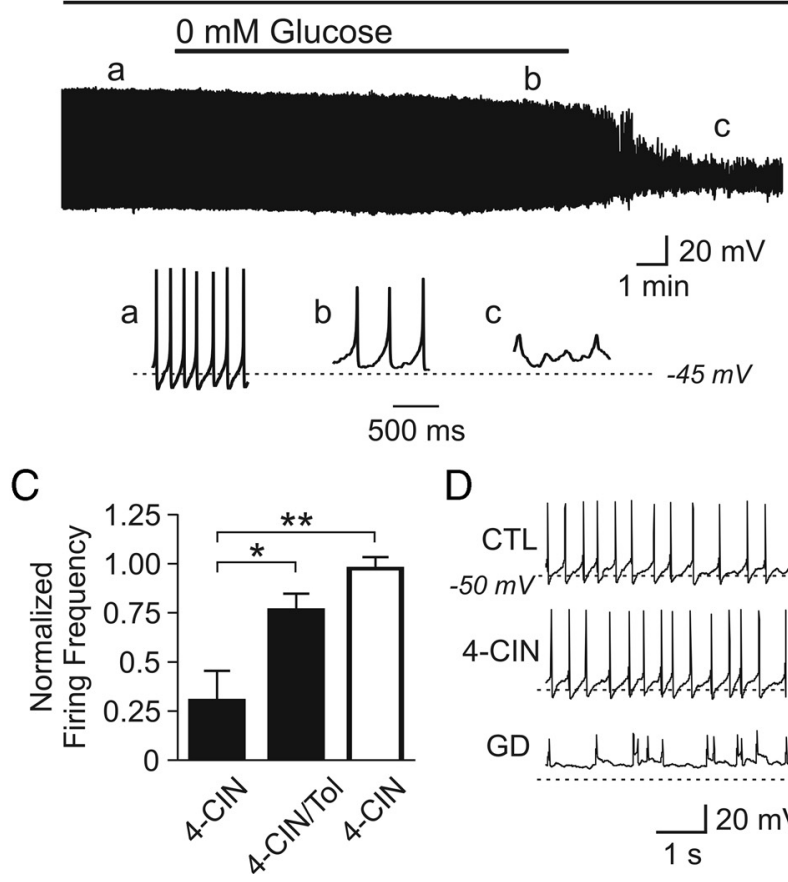

D

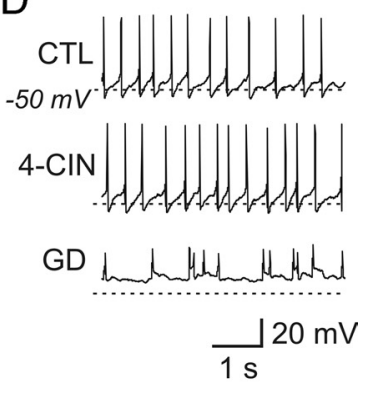

Figure 3. KATP channels mediate hyperpolarization induced by a lack of energy substrate. $A$, Representative current-clamp trace showing a spontaneously active orexin neuron silenced by glucose-free ACSF. $B$, KATP channel blockade prevents the hyperpolarization induced by 0 mм glucose. Note that glibenclamide unmasks a depolarization. The bottom panels show expanded traces taken at time points denoted by $\boldsymbol{a}-\boldsymbol{c}$. C, KATP channel blockade with tolbutamide (Tol) attenuates the inhibitory effect of 4 -CIN in orexin neurons (filled bars). In contrast, 4-CIN alone has no effect on the firing frequency of neurons in the arcuate nucleus (hollow bar). D, Current-clamp traces from one of the recorded arcuate neurons. These neurons do not respond to 4-CIN (middle panel) but cannot maintain healthy action potentials when faced with 20 min glucose deprivation (GD) (bottom panel). ${ }^{*} p<0.05{ }^{* *} p<0.01$. Error bars indicate SEM.

Next, we asked whether physiologically relevant glucose concentrations were converted to distinct endogenous levels of lactate. Glucose concentrations were changed from 2.5 to $1 \mathrm{~mm}$ in $0.5 \mathrm{~mm}$ increments, a range that corresponds to meal-to-meal fluctuations in the brain (Routh, 2002). Slices were allowed to adjust to each concentration for 30-60 min while the spontaneous firing frequency of orexin neurons was analyzed using conventional whole-cell mode. Using this paradigm, we found that, on average, the firing activity was independent of glucose concentration $(n=9-12)$ (Fig. $5 B)$. Nonetheless, the firing frequency varied among different orexin neurons, leaving a possibility that some neurons increased or decreased their firing in response to glucose fluctuations. To test this possibility, we repeatedly monitored the activity of individual orexin neurons in cell-attached mode while gradually decreasing the extracellular glucose concentration from 2.5 to $1 \mathrm{mM}(n=3)$ or increasing from 1 to 2.5 $\mathrm{mm}(n=2)$ in $0.5 \mathrm{~mm}$ increments. Again, there was no difference in the activity within this range (Fig. $5 C, D$ ). 

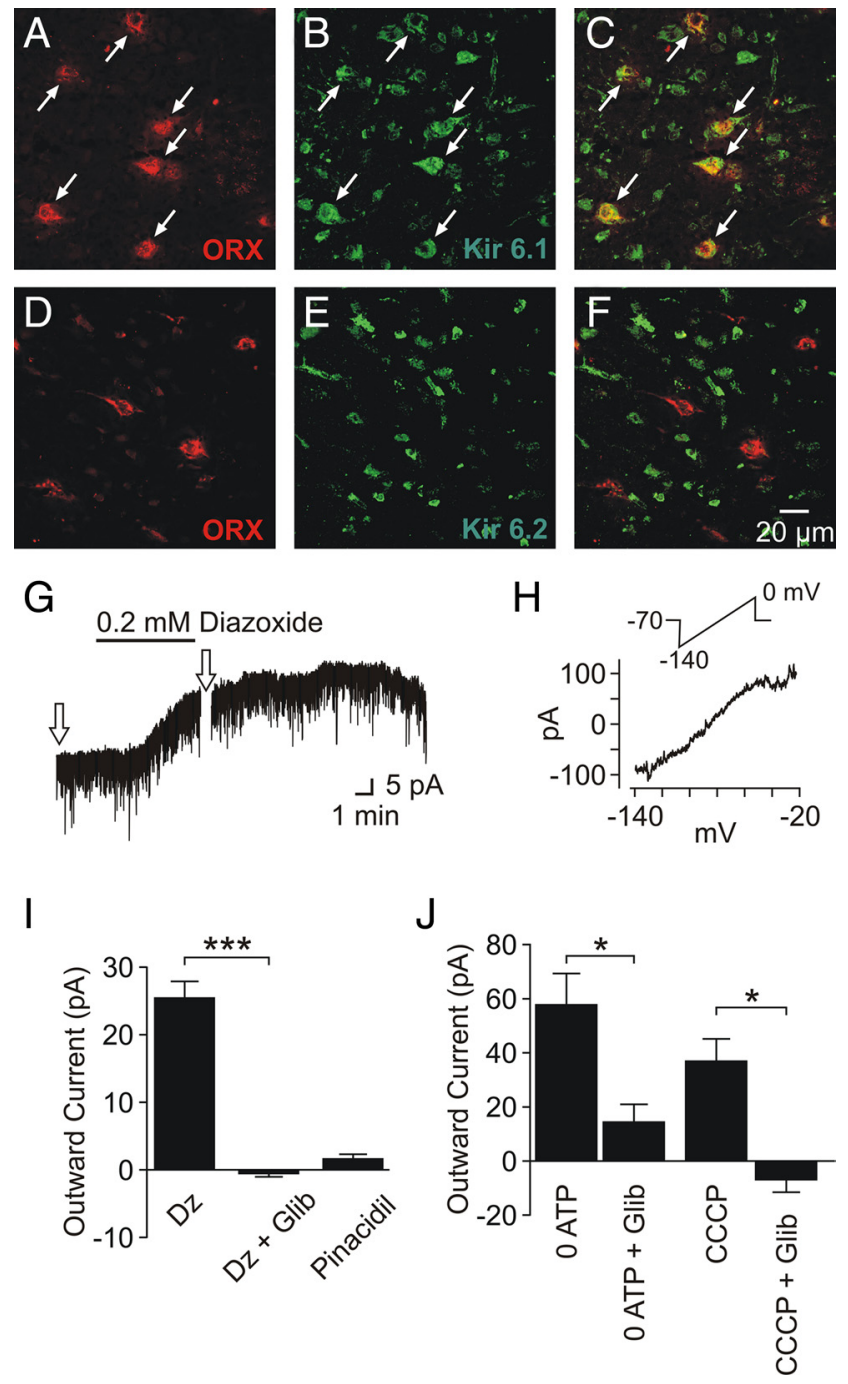

Figure 4. KATP channel composition in orexin neurons. $\boldsymbol{A}-\boldsymbol{C}$, Immunofluorescence labeling of orexin $A$ (red) $(\boldsymbol{A})$ and Kir6.1 (green) $(\boldsymbol{B})$ displays colocalization (C). D-F, Immunofluorescence labeling of orexin $A($ red) $(\boldsymbol{D})$ and Kir6.2 (green) $(\boldsymbol{E})$ displays a lack of colocalization $(\boldsymbol{F})$. $\boldsymbol{G}$, Diazoxide induces an outward current in the presence of TTX. The arrows indicate the times of voltage ramp applications. $\boldsymbol{H}$, Current-voltage relationship of the diazoxide-induced response, generated by subtracting the current response to voltage ramps in the baseline condition from that in the presence of diazoxide. The inset denotes the voltage ramp protocol used. I, Grouped data showing diazoxide $(D z)$ and pinacidil effects on orexin neurons. Diazoxide effect was significantly blocked by glibenclamide (Glib). J, Outward currents are also induced by postsynaptic dialysis with ATP-free internal solution (0 ATP) and CCCP. These currents are significantly blocked by glibenclamide. ${ }^{*} p<0.05 ;{ }^{* * *} p<0.005$. Error bars indicate SEM.

We then sought to determine whether the lack of changes in firing activity between 1 and $2.5 \mathrm{~mm}$ glucose was because the endogenous lactate level had reached a plateau at $1 \mathrm{~mm}$ glucose or because the ability of orexin neurons to convert lactate availability into firing frequency was saturated. Since 4-CIN is a competitive blocker that competes against lactate for MCTs, using a lower concentration of this compound allowed us to monitor relative levels of endogenous lactate (Bröer et al., 1999). Brain slices were incubated in ACSF with 1 or $2.5 \mathrm{~mm}$ glucose, in combination with a lower concentration of 4-CIN for 30-60 min. As shown in Figure $5 E$, conventional whole-cell recordings revealed that 4-CIN (0.1 mM) had no significant effect at $2.5 \mathrm{~mm}$ glucose ( $n=19$ for $2.5 \mathrm{~mm}$ glucose alone; $n=13$ for $2.5 \mathrm{~mm}$ glucose $/ 0.1$ $\mathrm{mm} 4$-CIN), whereas the same concentration of 4-CIN in combination with $1 \mathrm{~mm}$ glucose significantly decreased the firing rate
A

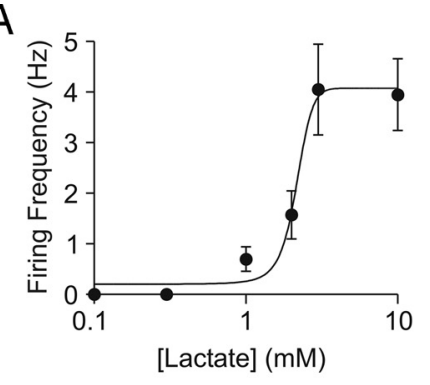

B

C

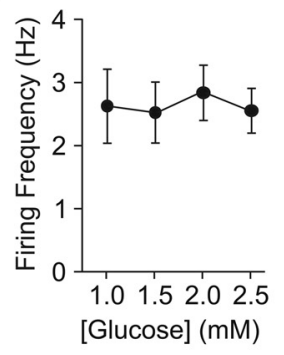

D
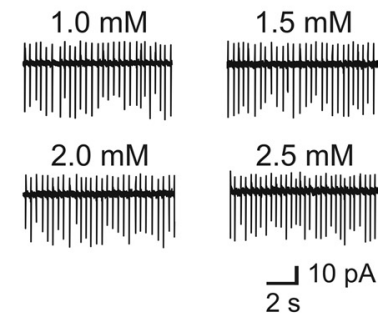

E

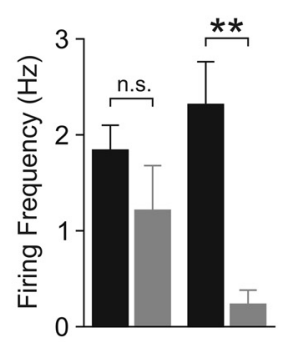

F

\section{$1 \mathrm{mM}$ Tolbutamide}

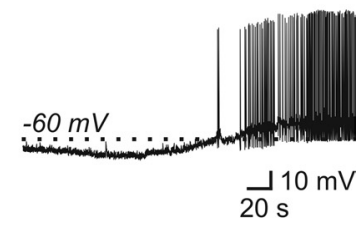

$[4-\mathrm{CIN}](\mathrm{mM}) \quad 0 \quad 0.1 \quad 0 \quad 0.1$

Figure 5. Orexin neurons are lactate sensors. $\boldsymbol{A}$, Firing rate is sensitive to the level of extracellular lactate. Glucose-free ACSF was used for these experiments. $\boldsymbol{B}$, Firing rate of orexin neurons in various glucose concentrations as indicated. Firing rate remained consistent from 1 to $2.5 \mathrm{~mm}$ glucose. $\boldsymbol{C}$, Repeated monitoring of the same neurons also reveals a lack of sensitivity to glucose fluctuation between 1 and $2.5 \mathrm{~mm}$. D, Sample traces from one of the recorded neurons in $\boldsymbol{C}$. $\boldsymbol{E}$, A low concentration of 4-CIN significantly inhibits orexin neurons in $1 \mathrm{~mm}$ glucose (GLU) but not in $2.5 \mathrm{~mm}$. $\boldsymbol{F}$, Cells exposed to $0.1 \mathrm{~mm} 4$-CIN and $1 \mathrm{~mm}$ glucose are readily depolarized by bath application of tolbutamide. ${ }^{* *} p<0.01$. n.s., Nonsignificant. Error bars indicate SEM.

of orexin neurons $(n=21$ for $1 \mathrm{mM}$ glucose; $n=11$ for $1 \mathrm{mM}$ glucose/0.1 mm 4-CIN). Cells incubated with $1 \mathrm{~mm}$ glucose and $0.1 \mathrm{~mm} 4$-CIN were depolarized by tolbutamide, suggesting that the low or lack of activity in this condition is attributable to the activation of KATP channels $(n=2)$ (Fig. $5 F)$. These findings suggest that $2.5 \mathrm{~mm}$ extracellular glucose results in more endogenous lactate release compared with $1 \mathrm{~mm}$ glucose. However, a steady firing frequency within this glucose range in the absence of 4-CIN (Fig. 5B-D) indicates that the metabolism-sensing mechanism involving KATP channels is saturated at $>1 \mathrm{~mm}$ glucose in our preparation. In support of this, only one of eight cells responded with an excitation when lactate ( $5 \mathrm{~mm}$; 4-5 min) was applied in addition to $2.5 \mathrm{~mm}$ glucose (data not shown).

Orexin neurons are less excitable in low extracellular glucose Brain glucose levels are known to drop as low as 0.2 (Silver and Erecinska, 1994) and $0.7 \mathrm{~mm}$ (de Vries et al., 2003) during insulin-induced hypoglycemia and overnight fasting, respectively. Thus, we also tested the effect of glucose concentrations $<1 \mathrm{~mm}$ for $20 \mathrm{~min}$ with cell-attached patch and found a reduc- 
tion in action potential frequency (Fig. $6 A, B)$. The effect was concentration dependent $\left(\mathrm{EC}_{50}=0.59 \mathrm{~mm}\right)$ (Fig. $6 C$ ), which was mainly attributable to a greater proportion of cells responding as the ambient glucose concentration became lower: 9 of 10 cells to $0 \mathrm{mM}, 4$ of 5 to $0.5 \mathrm{mM}, 3$ of 7 to $0.75 \mathrm{~mm}$, and 0 of 5 cells to $1 \mathrm{~mm}$ (Fig. 6D). Increasing glucose from 2.5 to $10 \mathrm{~mm}$ for 20 min had no effect on firing frequency $(n=$ 5) (Fig. 6C,D). For those that responded, the latency to inhibition was independent of glucose concentration (Fig. 6E). Thus, KATP channels in orexin neurons can be activated by the low range of physiologically relevant glucose concentrations.

An increase in membrane resistance because of lactate-induced closure of potassium channels can be expected to make orexin neurons more sensitive to subsequent stimulations. To test this idea, the response of orexin neurons to positive current injections was recorded in the absence or presence of lactate $(5 \mathrm{~mm})$. Hypothalamic slices were initially incubated in $0.5 \mathrm{~mm}$ glucose for at least $20 \mathrm{~min}$ to activate KATP channels. In this condition, an incremental current injection through the conventional whole-cell recording pipette (from 0 to $100 \mathrm{pA}$ over $5 \mathrm{~s}$ ) induced a gradual increase in firing frequency in every cell tested. When lactate was applied, both the baseline activity (without lactate, $0.2 \pm 0.1 \mathrm{~Hz}$; with lactate, $2.3 \pm 0.7 \mathrm{~Hz} ; n=8 ; p<0.05$ ) and the rate of increase in firing frequency during current injection (without lactate, $0.10 \pm 0.025 \mathrm{~Hz} / \mathrm{pA}$; with lactate, $0.13 \pm 0.020$ $\mathrm{Hz} / \mathrm{pA} ; n=8 ; p<0.05$ ) became significantly higher (Fig. 7). These data demonstrate that low availability of energy substrate not only decreases the basal firing rate of orexin neurons but also blunts their excitability to subsequent inputs.

\section{Short-term glucose effect}

The inhibitory effect demonstrated above had relatively long latencies ( $>10 \mathrm{~min})$. In contrast, it has been shown that an increase or decrease in extracellular glucose induces a robust inhibition or excitation, respectively, within several minutes in the majority of orexin neurons examined (Yamanaka et al., 2003; Burdakov et al., 2005). Thus, the short-term effect (2-5 min) of glucose recorded with cell-attached patch was also analyzed. Surprisingly, no robust or consistent short-term effects were seen in our hands (Fig. 8A; supplemental Fig. 1, available at www.jneurosci.org as supplemental material), even with the same combinations of glucose concentrations, ACSF, and/or internal solution as previously reported (Burdakov et al., 2006; González et al., 2008) (Fig. $8 B$ ). We also tried dissolving glucose immediately before experiments to increase the proportion of $\alpha$ - over $\beta$-anomer, since glucose powder contains predominantly $\alpha$-D- $(+)$-glucose, which converts to $\beta$-D- $(+)$-glucose over a few hours in solution, reaching equilibrium of $\alpha: \beta=36: 64$. However, this made no difference. As previous reports used mice (C57BL/6 background) (Yamanaka et al., 2003; Burdakov et al., 2005; Guyon et al., 2009), we also examined orexin neurons in 3- to 5-week-old C57BL/ $6 \mathrm{NCrl}$ mice and again observed no robust inhibition in response to glucose increases from 1 to $5 \mathrm{~mm}$ (Fig. $8 B$ ). Nonetheless,
$\mathrm{B}$

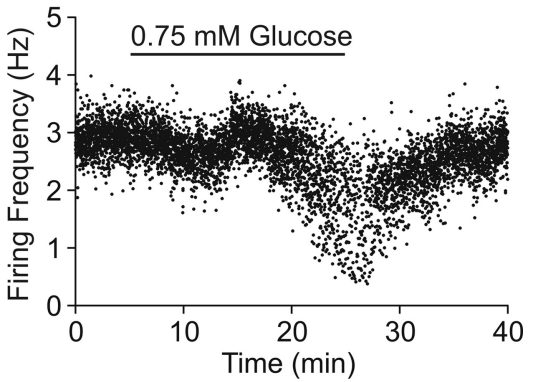

$\mathrm{E}$

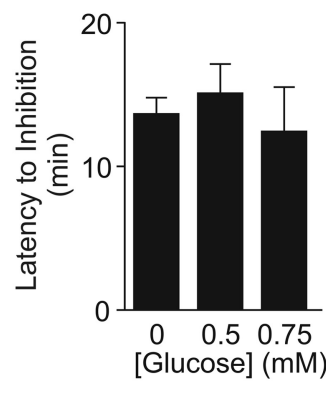

[Glucose] (mM)

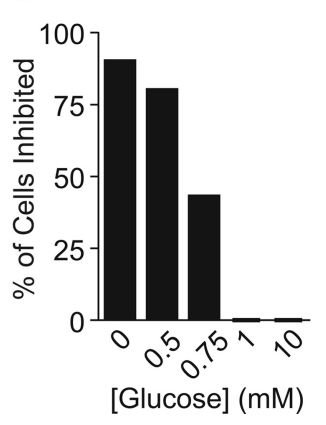

\section{.}

Figure 6. Orexin neurons are less active in low glucose concentrations. $\boldsymbol{A}, \boldsymbol{B}$, Representative experiments showing that decreasing extracellular glucose from 2.5 to $0.5(\boldsymbol{A})$ or to $0.75 \mathrm{~mm}(\boldsymbol{B})$ inhibits spontaneous firing. $\boldsymbol{C}$, Concentration-response curve fitted average firing frequency of orexin neurons. Baseline frequency in $2.5 \mathrm{~mm}$ glucose was used to normalize data. $D$, Percentage of orexin neurons inhibited by a 20 min shift in glucose concentration. $\boldsymbol{E}$, Latency to inhibition is independent of final glucose concentration. Error bars indicate SEM.

switching from 10 to $0 \mathrm{~mm}$ induced a modest excitation (Fig. $8 B, C$ ), providing some support for the GI response in mouse orexin neurons. The inhibitory effect of long-term $0 \mathrm{~mm}$ glucose application was also observed in mice $(n=3)$ (Fig. $8 C$ ), albeit with a longer latency compared with rats (Fig. $8 D$ ), suggesting this is a common phenomenon in both species, but more sensitive in rats.

We also considered the functional heterogeneity of orexin neurons. It has been proposed that orexin neurons located in the lateral hypothalamus (LH) (lateral to the fornix) are functionally distinct from those in the perifornical area (PFA) (dorsal and dorsomedial to the fornix) (Harris and Aston-Jones, 2006). Furthermore, individual orexin neurons have been characterized as either D- or H-type depending on the presence or absence, respectively, of action potentials immediately on relief from a hyperpolarizing current step. These subpopulations have been shown to display different responses to glucose (Williams et al., 2008). Thus, we investigated whether the cell location or electrophysiological type determined the short-term response to glucose in the present study. Orexin neurons that were nonresponsive to glucose were found in both the LH and PFA and consisted of both Dand $\mathrm{H}$-type (Fig. $8 E$ ). In contrast, all responders (GE and GI) were found in the PFA and all but one (six of seven) were H-type orexin neurons. Therefore, in our hands, 6 of $12 \mathrm{H}$-type cells that existed in the PFA responded to short-term glucose changes, whereas only 1 of 16 D-type cells in LH or PFA responded. It remains to be seen whether $\mathrm{H}$-type neurons in the $\mathrm{LH}$ also respond in the same manner because of the low total number of this neuron type examined.

\section{Discussion}

\section{Orexin neurons prefer lactate over glucose as an} energy substrate

The present study demonstrates that orexin neurons depend on astrocyte-derived lactate as their main energy supply. Blockade of 
A

$0 \mathrm{pA}$

$100 \mathrm{pA}$

LE

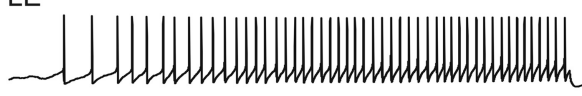

HE

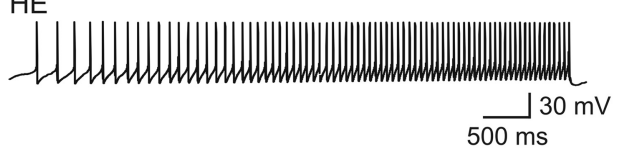

$\mathrm{B}$
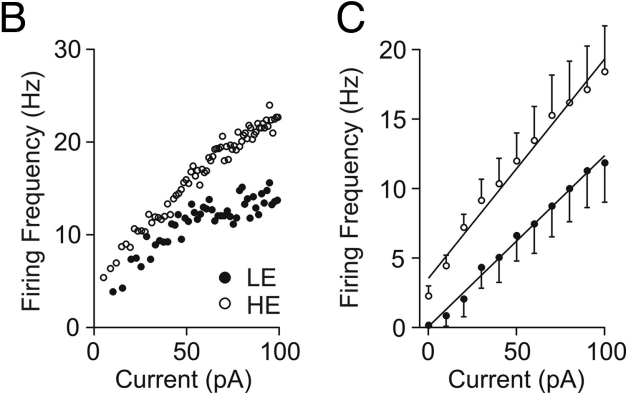

Figure 7. Lactate increases the excitability of orexin neurons. $A$, Typical responses to positive current ramps from 0 to $100 \mathrm{pA}(5 \mathrm{~s})$ in low-energy (LE) $(0.5 \mathrm{~mm}$ glucose) and high-energy (HE) ( $0.5 \mathrm{~mm}$ glucose plus $5 \mathrm{~mm}$ lactate) conditions. $\boldsymbol{B}$, Instantaneous firing rate of a representative cell during the incremental current injection for LE (filled circles) or HE (hollow circles) condition. C, Grouped data showing average firing frequency in $10 \mathrm{pA}$ bins. Error bars indicate SEM.

MCTs mostly attenuates the spontaneous firing of these neurons despite the presence of glucose, suggesting that lactate uptake through MCTs is required. Thus, our study supports the astrocyte-neuron shuttle hypothesis that proposes the importance of astrocyte-derived lactate as a neuronal fuel (Pellerin and Magistretti, 1994). The excitatory effect of lactate on the firing frequency was concentration dependent, suggesting that orexin neurons are lactate sensors capable of detecting differences in extracellular lactate levels. Almost exclusive dependence on lactate indicates that orexin neurons can be influenced by not only the absolute levels of brain glucose but also the efficiency of glucose conversion to lactate, lactate release by astrocytes, and uptake by neurons, for example, during excitatory transmission (Pellerin and Magistretti, 1994), oxidative stress (Liddell et al., 2009), high-fat diet (Pierre et al., 2007), and hypoxia (Véga et al., 2006). Nonetheless, we cannot overlook the possibility that energy substrates additional to lactate may act as a significant fuel source for orexin neurons in vivo, which deserves future investigation.

KATP current was found to underlie the reduced excitability. In the absence of glucose and KATP current, orexin neurons develop irreversible depolarization, suggesting that lactate is also necessary for maintaining normal membrane potential and that KATP channels play a neuroprotective role. These results are similar to the effects of hypoxia on substantia nigra neurons, where activation of KATP current induces hyperpolarization in wild-type neurons, whereas depolarization develops in Kir6.2knock-out neurons (Yamada et al., 2001).

Orexin neurons can temporarily maintain activity in the absence of an extracellular energy source, as it takes 10-20 min for glucose deprivation or 4-CIN to take effect. This may be attributable to astrocytes continuing to release lactate or neurons having their own energy store. The former is unlikely, since disconnecting the lactate shuttle from astrocytes to neurons with 4-CIN does not curtail the latency. Therefore, it appears that orexin neurons have an endogenous supply to support themselves. It has been estimated that neurons contain $>20 \mathrm{~mm}$ intra-
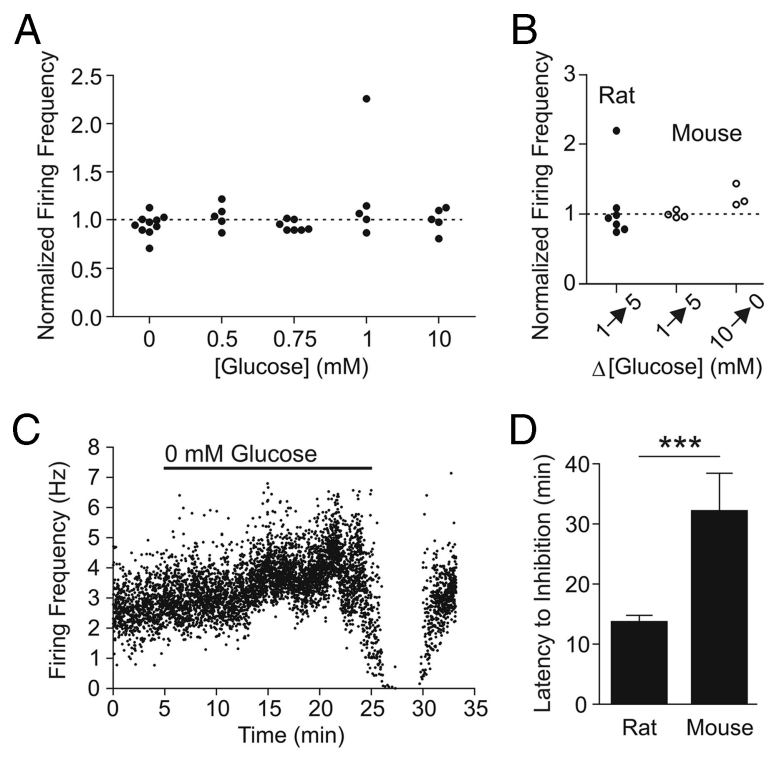

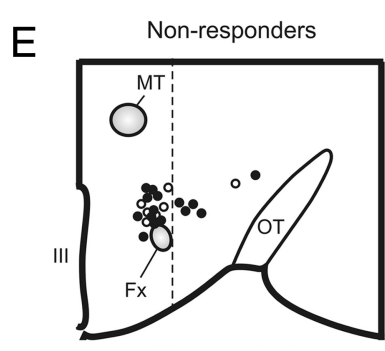

Glucose-Excited

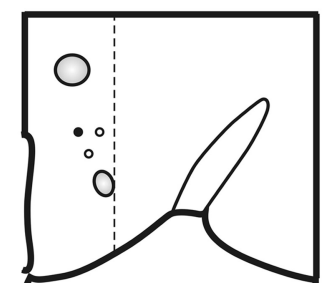

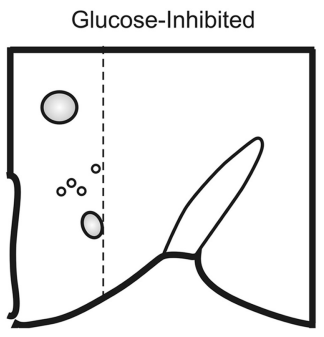

- D-Type

o H-Type
Figure 8. Lack of consistent short-term glucose effects on action potential firing. $\boldsymbol{A}$, Normalized firing frequency of rat orexin neurons during the acute phase (2-5 min) of a new glucose concentration as indicated, from a baseline of $2.5 \mathrm{~mm}$. For the 0 mm experiments, a subset of cells was exposed to a baseline of $10 \mathrm{~mm}$ glucose. $\boldsymbol{B}$, Normalized firing frequency of orexin neurons after glucose changes as indicated in rats (filled circles) and mice (hollow circles). For experiments on rats, ACSF and pipette solutions were adapted from previous studies (Burdakov et al., 2006; González et al., 2008). C, D, Glucose deprivation-induced inhibition is also present in mouse orexin neurons, albeit with a longer latency compared with rats $(\boldsymbol{D})$. Glucose deprivation exceeding 20 min was tested on some mouse orexin neurons. $\boldsymbol{E}$, Schematic of recorded orexin neurons in a hemisected hypothalamus showing the location, electrophysiological type (D vs H) and short-term responsiveness to glucose. Bilateral and anteroposterior dispersal is collapsed into one map to display the distribution pattern relative to the fornix and the third ventricle. Only cells of which the location could be clearly identified by post hoc immunofluorescence labeling are shown. Fx, Fornix; MT, mammillothalamic tract; 0T, optic tract; III, third ventricle. The dotted lines denote the lateral border between the perifornical area and lateral hypothalamus. ${ }^{* *} p<0.001$. Error bars indicate SEM.

cellular lactate (Walz and Mukerji, 1988), which may be a provisional energy substrate.

\section{Technical considerations}

Although perforated and cell-attached patch-clamp methods were essential for the present study, conventional whole-cell mode was also used. It allowed us to characterize the electrophysiological properties and monitor the basal activity from a number of orexin cells within a limited time frame. Importantly, in our 
hands, the baseline firing rates in $2.5 \mathrm{~mm}$ glucose during the first $1.5 \mathrm{~min}$ of wholecell recordings $(n=19)$ were not significantly different from those in stable $(>5$ min) cell-attached recordings $(n=42$; $p>0.05$ ) (supplemental Fig. 2, available at www.jneurosci.org as supplemental material). This suggests that the wholecell configuration did not influence the firing activity at least for the first $1.5 \mathrm{~min}$, consistent with a previous report (van den Top et al., 2007). To further support our contention that whole-cell recordings did not affect our result, we found that ATPfree internal solution took at least $5 \mathrm{~min}$ after break-in to have any effect on the holding current. Furthermore, different concentrations of lactate were found to induce distinct firing rates in whole-cell mode. Thus, it is unlikely that, during the period in which our recordings were taken, ATP in the recording pipette would have significantly influenced the membrane potential and firing frequency.

\section{Consideration of discrepancies in the literature}

Previous reports have demonstrated an acute inhibitory effect of glucose on a majority of orexin neurons (Burdakov et al., 2005; González et al., 2008; Guyon et al., 2009), whereas others suggest that orexin neurons are not or not always inhibited by glucose (Liu et al., 2001; Muroya et al., 2001). We did not find a consistent short-term effect despite testing various recording methods and accounting for a number of variables, regardless of the location or electrophysiological properties of orexin neurons. Our results support a previous proposal that hypoglycemia-induced excitation of orexin neurons in vivo is attributable to an indirect mechanism (Cai et al., 2001).

Since studies showing a consistent GI effect used mice, whereas others, including ours, have found otherwise using rats, the discrepancy may stem from a species difference. However, on investigation of mouse neurons, only a modest GI effect was detected if any. Importantly, glucose deprivation also activated KATP channels in mice, albeit with a longer latency than rats. Therefore, the properties of orexin neurons in different species may not be identical. Also, there may be developmental changes in glucose sensitivity. Studies demonstrating the GI response used brain slices from 2- to 4-week-old mice (mostly 2-3 weeks) (Burdakov et al., 2005, 2006; González et al., 2008; Guyon et al., 2009), whereas we used 3- to 4 -week-old mice and rats.

The inhibitory and excitatory effects of glucose are not necessarily exclusive of each other, because the GI effect is observed at concentrations $>1 \mathrm{~mm}$ (Burdakov et al., 2005), whereas the KATP channel-mediated effect is activated below $1 \mathrm{~mm}$. Under certain conditions in which both mechanisms are functional, it should result in a parabolic relationship between extracellular glucose concentration and firing frequency of orexin neurons.

\section{KATP channels mediate energy sensing in orexin neurons} Neuronal inhibition in glucose-free conditions has been described as a "ubiquitous" (Mobbs et al., 2001) "run-out-of-fuel" phenomenon, distinct from glucosensing (González et al., 2009).
(1)

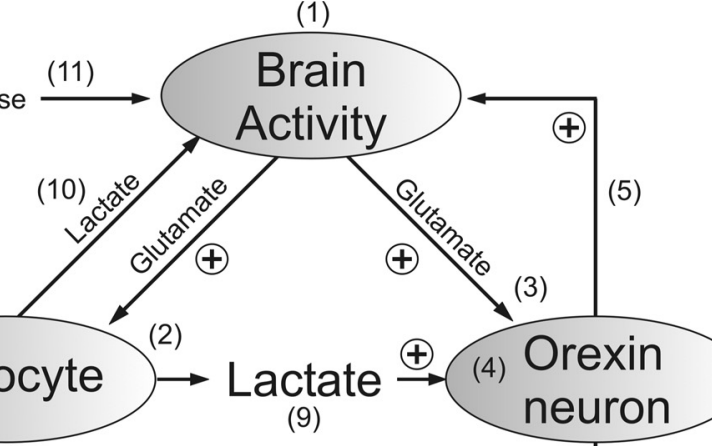

(7)

Food

Intake

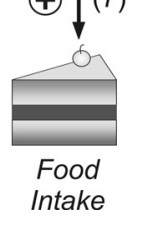

Figure 9. Orexin neurons as lactate sensors. Schematic drawing depicting a potential mechanism for matching energy sub-
strate supply and brain activity based on the present study and available literature. High levels of brain activity (1) activates orexin in other availability, arousal, and brain activity.

However, we failed to see any hyperpolarizing response to either MCT blockade or prolonged glucose deprivation in arcuate neurons, suggesting that hyperpolarization is not a universal response to glucose depletion. Additionally, we found that orexin neurons show a concentration-dependent response to low but physiologically relevant glucose concentrations.

GE neurons in the ventromedial hypothalamus and arcuate nucleus metabolize glucose and produce ATP, which results in the modulation of KATP channels that mediate the glucosensitivity (Ashford et al., 1990; Miki et al., 2001; Kang et al., 2006; van den Top et al., 2007). These neurons are also excited by lactate, suggesting that they are in fact glucose/lactate sensors (Yang et al., 1999; Ainscow et al., 2002). Despite possessing the same type of ion channels, orexin neurons differ from these typical glucosensors. First, our study shows that orexin neurons do not detect glucose directly, likely because of a lack of glucokinase (DunnMeynell et al., 2002). Second, the indirect glucose sensitivity saturates above $1 \mathrm{~mm}$ glucose. It remains to be seen whether this concentration dependence differs in other conditions such as synaptic activation or hypoxia in which lactate production is enhanced (Pellerin and Magistretti, 1994; Véga et al., 2006). Third, glucosensing neurons typically express Kir6.2/SUR1 channels (Levin et al., 1999; Miki et al., 2001), whereas orexin neurons express Kir6.1/SUR1 channels, similar to glucose-receptive neurons in the ventromedial hypothalamus (Lee et al., 1999). Since Kir6.2 is more sensitive to metabolic state than Kir6.1 (Gribble et al., 1997), a Kir6.1/SUR1 may be less sensitive than Kir6.2/SUR1. Finally, the output of orexin neurons differs from typical anabolic or catabolic neurons. Orexin neurons increase both energy intake and expenditure (Sakurai, 2007), whereas glucose homeostatic neurons inversely regulate energy intake and expenditure. Together, despite the presence of functional KATP channels, the 
influence of energy substrates on orexin neurons is different from previously described glucosensors, and it is unlikely that these neurons are involved in counterregulatory responses for glucose homeostasis.

\section{Physiological significance}

We have demonstrated that lactate disinhibits and primes orexin neurons for excitation (i.e., increases spontaneous firing and the sensitivity to a given excitatory input, respectively). As glutamate stimulates lactate production in astrocytes (Pellerin and Magistretti, 1994), our result indicates that excitatory inputs from other brain areas would have a dual excitatory effect on orexin neurons. Also, since orexin neurons coexpress glutamate (Rosin et al., 2003), an activated orexin neuron may trigger a lactatemediated positive feedback and recruitment of other orexin neurons. Furthermore, MCTs are proton/monocarboxylate symporters, meaning lactate release accompanies local decline in extracellular $\mathrm{pH}$. Since orexin neurons are excited by low $\mathrm{pH}$ (Williams et al., 2007), lactate combined with a drop in $\mathrm{pH}$ would be expected to have additive excitatory effects. Together, it appears that excitatory synaptic inputs activate orexin neurons more effectively when accompanied by lactate that signals adequate energy supply. Activated orexin neurons, in turn, will promote or maintain wakefulness, and increase food intake and hepatic glucose production. Thus, we propose that orexin neurons play an essential role in gating brain activation in accordance with energy supply and activating physiological responses to meet the energy demands of elevated brain activity (Fig. 9). Indeed, extracellular lactate in the brain reaches a higher concentration during the active/awake phase compared with the inactive/sleep phase (Shram et al., 2002), and the discharge of orexin neurons follows a strikingly similar pattern (Lee et al., 2005; Mileykovskiy et al., 2005).

In conclusion, our study highlights lactate as an important regulator of the orexin system. Lactate is not only an energy substrate but also a paracrine factor that signals the levels of brain activity and fuel availability to orexin neurons. KATP channels play a critical role in this astrocyte-orexin neuron coupling, while also providing neuroprotection. Additional investigation of lactate sensors within the CNS is essential for a full understanding of the role of lactate in brain energetics.

\section{References}

Ainscow EK, Mirshamsi S, Tang T, Ashford ML, Rutter GA (2002) Dynamic imaging of free cytosolic ATP concentration during fuel sensing by rat hypothalamic neurones: evidence for ATP-independent control of ATPsensitive $\mathrm{K}^{+}$channels. J Physiol 544:429-445.

Alberto CO, Trask RB, Quinlan ME, Hirasawa M (2006) Bidirectional dopaminergic modulation of excitatory synaptic transmission in orexin neurons. J Neurosci 26:10043-10050.

Ashford ML, Boden PR, Treherne JM (1990) Glucose-induced excitation of hypothalamic neurones is mediated by ATP-sensitive $\mathrm{K}^{+}$channels. Pflugers Arch 415:479-483.

Balfour RH, Hansen AM, Trapp S (2006) Neuronal responses to transient hypoglycaemia in the dorsal vagal complex of the rat brainstem. J Physiol 570:469-484.

Bröer S, Bröer A, Schneider HP, Stegen C, Halestrap AP, Deitmer JW (1999) Characterization of the high-affinity monocarboxylate transporter MCT2 in Xenopus laevis oocytes. Biochem J 341:529-535.

Burdakov D, Gerasimenko O, Verkhratsky A (2005) Physiological changes in glucose differentially modulate the excitability of hypothalamic melanin-concentrating hormone and orexin neurons in situ. J Neurosci 25:2429-2433.

Burdakov D, Jensen LT, Alexopoulos H, Williams RH, Fearon IM, O'Kelly I, Gerasimenko O, Fugger L, Verkhratsky A (2006) Tandem-pore $\mathrm{K}^{+}$ channels mediate inhibition of orexin neurons by glucose. Neuron 50:711-722.

Cai XJ, Evans ML, Lister CA, Leslie RA, Arch JR, Wilson S, Williams G (2001) Hypoglycemia activates orexin neurons and selectively increases hypothalamic orexin-B levels: responses inhibited by feeding and possibly mediated by the nucleus of the solitary tract. Diabetes 50:105-112.

Date Y, Ueta Y, Yamashita H, Yamaguchi H, Matsukura S, Kangawa K, Sakurai T, Yanagisawa M, Nakazato M (1999) Orexins, orexigenic hypothalamic peptides, interact with autonomic, neuroendocrine and neuroregulatory systems. Proc Natl Acad Sci U S A 96:748-753.

de Vries MG, Arseneau LM, Lawson ME, Beverly JL (2003) Extracellular glucose in rat ventromedial hypothalamus during acute and recurrent hypoglycemia. Diabetes 52:2767-2773.

Dunn-Meynell AA, Routh VH, Kang L, Gaspers L, Levin BE (2002) Glucokinase is the likely mediator of glucosensing in both glucose-excited and glucose-inhibited central neurons. Diabetes 51:2056-2065.

Eggermann E, Bayer L, Serafin M, Saint-Mleux B, Bernheim L, Machard D, Jones BE, Mühlethaler M (2003) The wake-promoting hypocretinorexin neurons are in an intrinsic state of membrane depolarization. J Neurosci 23:1557-1562.

Ferguson AV, Samson WK (2003) The orexin/hypocretin system: a critical regulator of neuroendocrine and autonomic function. Front Neuroendocrinol 24:141-150.

González JA, Jensen LT, Fugger L, Burdakov D (2008) Metabolismindependent sugar sensing in central orexin neurons. Diabetes 57:2569-2576.

González JA, Reimann F, Burdakov D (2009) Dissociation between sensing and metabolism of glucose in sugar sensing neurones. J Physiol 587:41-48.

Gribble FM, Ashfield R, Ammala C, Ashcroft FM (1997) Properties of cloned ATP-sensitive $\mathrm{K}^{+}$currents expressed in Xenopus oocytes. J Physiol 498:87-98.

Guyon A, Tardy MP, Rovère C, Nahon JL, Barhanin J, Lesage F (2009) Glucose inhibition persists in hypothalamic neurons lacking tandem-pore $\mathrm{K}^{+}$channels. J Neurosci 29:2528-2533.

Hagan JJ, Leslie RA, Patel S, Evans ML, Wattam TA, Holmes S, Benham CD, Taylor SG, Routledge C, Hemmati P, Munton RP, Ashmeade TE, Shah AS, Hatcher JP, Hatcher PD, Jones DN, Smith MI, Piper DC, Hunter AJ, Porter RA, et al. (1999) Orexin A activates locus coeruleus cell firing and increases arousal in the rat. Proc Natl Acad Sci U S A 96:10911-10916.

Harris GC, Aston-Jones G (2006) Arousal and reward: a dichotomy in orexin function. Trends Neurosci 29:571-577.

Hirasawa M, Mouginot D, Kozoriz MG, Kombian SB, Pittman QJ (2003) Vasopressin differentially modulates non-NMDA receptors in vasopressin and oxytocin neurons in the supraoptic nucleus. J Neurosci 23:4270-4277.

Kang L, Routh VH, Kuzhikandathil EV, Gaspers LD, Levin BE (2004) Physiological and molecular characteristics of rat hypothalamic ventromedial nucleus glucosensing neurons. Diabetes 53:549-559.

Kang L, Dunn-Meynell AA, Routh VH, Gaspers LD, Nagata Y, Nishimura T, Eiki J, Zhang BB, Levin BE (2006) Glucokinase is a critical regulator of ventromedial hypothalamic neuronal glucosensing. Diabetes 55:412-420.

Lee K, Dixon AK, Richardson PJ, Pinnock RD (1999) Glucose-receptive neurones in the rat ventromedial hypothalamus express KATP channels composed of Kir6.1 and SUR1 subunits. J Physiol 515:439-452.

Lee MG, Hassani OK, Jones BE (2005) Discharge of identified orexin/hypocretin neurons across the sleep-waking cycle. J Neurosci 25:6716-6720.

Levin BE (2001) Glucosensing neurons do more than just sense glucose. Int J Obes Relat Metab Disord 25 [Suppl 5]:S68-S72.

Levin BE, Dunn-Meynell AA, Routh VH (1999) Brain glucose sensing and body energy homeostasis: role in obesity and diabetes. Am J Physiol 276:R1223-R1231.

Levin BE, Routh VH, Kang L, Sanders NM, Dunn-Meynell AA (2004) Neuronal glucosensing: what do we know after 50 years? Diabetes 53:2521-2528.

Liddell JR, Zwingmann C, Schmidt MM, Thiessen A, Leibfritz D, Robinson SR, Dringen R (2009) Sustained hydrogen peroxide stress decreases lactate production by cultured astrocytes. J Neurosci Res 87:2696-2708.

Liu XH, Morris R, Spiller D, White M, Williams G (2001) Orexin A preferentially excites glucose-sensitive neurons in the lateral hypothalamus of the rat in vitro. Diabetes 50:2431-2437. 
Lynch RM, Tompkins LS, Brooks HL, Dunn-Meynell AA, Levin BE (2000) Localization of glucokinase gene expression in the rat brain. Diabetes 49:693-700.

Magistretti PJ, Pellerin L, Martin JL (1995) Brain energy metabolism: an integrated cellular perspective. In: Neuropsychopharmacology: the fourth generation of progress (Bloom F, Kupfer DJ, eds), pp 657-670. New York: Lippincott Williams and Wilkins.

Marty N, Dallaporta M, Thorens B (2007) Brain glucose sensing, counterregulation, and energy homeostasis. Physiology 22:241-251.

Miki T, Liss B, Minami K, Shiuchi T, Saraya A, Kashima Y, Horiuchi M, Ashcroft F, Minokoshi Y, Roeper J, Seino S (2001) ATP-sensitive K ${ }^{+}$ channels in the hypothalamus are essential for the maintenance of glucose homeostasis. Nat Neurosci 4:507-512.

Mileykovskiy BY, Kiyashchenko LI, Siegel JM (2005) Behavioral correlates of activity in identified hypocretin/orexin neurons. Neuron 46:787-798.

Mobbs CV, Kow LM, Yang XJ (2001) Brain glucose-sensing mechanisms: ubiquitous silencing by aglycemia vs. hypothalamic neuroendocrine responses. Am J Physiol Endocrinol Metab 281:E649-E654.

Muroya S, Uramura K, Sakurai T, Takigawa M, Yada T (2001) Lowering glucose concentrations increases cytosolic $\mathrm{Ca}^{2+}$ in orexin neurons of the rat lateral hypothalamus. Neurosci Lett 309:165-168.

Pellerin L, Magistretti PJ (1994) Glutamate uptake into astrocytes stimulates aerobic glycolysis: a mechanism coupling neuronal activity to glucose utilization. Proc Natl Acad Sci U S A 91:10625-10629.

Pellerin L, Bouzier-Sore AK, Aubert A, Serres S, Merle M, Costalat R, Magistretti PJ (2007) Activity-dependent regulation of energy metabolism by astrocytes: an update. Glia 55:1251-1262.

Pierre K, Parent A, Jayet PY, Halestrap AP, Scherrer U, Pellerin L (2007) Enhanced expression of three monocarboxylate transporter isoforms in the brain of obese mice. J Physiol 583:469-486.

Rosin DL, Weston MC, Sevigny CP, Stornetta RL, Guyenet PG (2003) Hypothalamic orexin (hypocretin) neurons express vesicular glutamate transporters VGLUT1 or VGLUT2. J Comp Neurol 465:593-603.

Routh VH (2002) Glucose-sensing neurons - are they physiologically relevant? Physiol Behav 76:403-413.

Sakurai T (2007) The neural circuit of orexin (hypocretin): maintaining sleep and wakefulness. Nat Rev Neurosci 8:171-181.

Sakurai T, Amemiya A, Ishii M, Matsuzaki I, Chemelli RM, Tanaka H, Williams SC, Richardson JA, Kozlowski GP, Wilson S, Arch JR, Buckingham RE, Haynes AC, Carr SA, Annan RS, McNulty DE, Liu WS, Terrett JA, Elshourbagy NA, Bergsma DJ, et al. (1998) Orexins and orexin receptors: a family of hypothalamic neuropeptides and $\mathrm{G}$ protein-coupled receptors that regulate feeding behavior. Cell 92:573-585.

Shram N, Netchiporouk L, Cespuglio R (2002) Lactate in the brain of the freely moving rat: voltammetric monitoring of the changes related to the sleep-wake states. Eur J Neurosci 16:461-466.

Silver IA, Erecinska M (1994) Extracellular glucose concentration in mammalian brain: continuous monitoring of changes during increased neuronal activity and upon limitation in oxygen supply in normo-, hypo-, and hyperglycemic animals. J Neurosci 14:5068-5076.

Song Z, Levin BE, McArdle JJ, Bakhos N, Routh VH (2001) Convergence of pre- and postsynaptic influences on glucosensing neurons in the ventromedial hypothalamic nucleus. Diabetes 50:2673-2681.

Tabernero A, Vicario C, Medina JM (1996) Lactate spares glucose as a metabolic fuel in neurons and astrocytes from primary culture. Neurosci Res 26:369-376.

van den Top M, Lyons DJ, Lee K, Coderre E, Renaud LP, Spanswick D (2007) Pharmacological and molecular characterization of ATP-sensitive $\mathrm{K}^{+}$ conductances in CART and NPY/AgRP expressing neurons of the hypothalamic arcuate nucleus. Neuroscience 144:815-824.

Véga C, Sachleben RL Jr, Gozal D, Gozal E (2006) Differential metabolic adaptation to acute and long-term hypoxia in rat primary cortical astrocytes. J Neurochem 97:872-883.

Voigt JP, Nwaiser B, Rex A, Mayer C, Fink H (2004) Effect of 5-HT1A receptor activation on hypothalamic glucose. Pharmacol Res 50:359-365.

Walz W, Mukerji S (1988) Lactate release from cultured astrocytes and neurons: a comparison. Glia 1:366-370.

Waniewski RA, Martin DL (1998) Preferential utilization of acetate by astrocytes is attributable to transport. J Neurosci 18:5225-5233.

Williams RH, Jensen LT, Verkhratsky A, Fugger L, Burdakov D (2007) Control of hypothalamic orexin neurons by acid and $\mathrm{CO}_{2}$. Proc Natl Acad Sci U S A 104:10685-10690.

Williams RH, Alexopoulos H, Jensen LT, Fugger L, Burdakov D (2008) Adaptive sugar sensors in hypothalamic feeding circuits. Proc Natl Acad Sci U S A 105:11975-11980.

Yamada K, Ji JJ, Yuan H, Miki T, Sato S, Horimoto N, Shimizu T, Seino S, Inagaki N (2001) Protective role of ATP-sensitive potassium channels in hypoxia-induced generalized seizure. Science 292:1543-1546.

Yamanaka A, Beuckmann CT, Willie JT, Hara J, Tsujino N, Mieda M, Tominaga M, Yagami K, Sugiyama F, Goto K, Yanagisawa M, Sakurai T (2003) Hypothalamic orexin neurons regulate arousal according to energy balance in mice. Neuron 38:701-713.

Yang XJ, Kow LM, Funabashi T, Mobbs CV (1999) Hypothalamic glucose sensor: similarities to and differences from pancreatic beta-cell mechanisms. Diabetes 48:1763-1772.

Yi CX, Serlie MJ, Ackermans MT, Foppen E, Buijs RM, Sauerwein HP, Fliers E, Kalsbeek A (2009) A major role for perifornical orexin neurons in the control of glucose metabolism in rats. Diabetes 58:1998-2005. 